\title{
MONISMO ANÔMALO, FISICALISMO, CAUSALIDADE MENTAL ${ }^{1}$
}

\author{
Andrea Schimmenti (UFBA) ${ }^{2}$ \\ andrea58.sch@gmail.com
}

Resumo: referindo-se a alguns aspectos do debate entre Donald Davidson e Jaegwon Kim acerca do problema da eficácia causal do mental no mundo físico, este artigo visa focalizar um ponto de tensão que parece surgir no âmbito do fisicalismo não reducionista davidsoniano, cuja expressão mais conhecida é o argumento do monismo anômalo, que pretende conciliar duas alegações dificilmente conciliáveis no âmbito de uma tese fisicalista. São estas, a alegação da anomalia do mental, que afirma a autonomia do mental do sistema das leis que governam os fenômenos físicos, e a alegação de que os eventos mentais e as ações humanas fazem parte do fluxo causal dos eventos da natureza. O Monismo Anômalo parece ser uma tese epifenomenalista, pois, no Monismo Anômalo, a alegação da anomalia do mental exclui que o mental possa ter uma eficácia causal.

Palavras-chave: mente; fisicalismo; causalidade mental; monismo anômalo.

Este artigo investiga um tema muito debatido no panorama contemporâneo da metafísica e da filosofia da mente, a saber, a relação entre mente e mundo natural, enfocada a partir da crítica de J. Kim ao argumento do monismo anômalo de D. Davidson. Na vida cotidiana, não costumamos duvidar que nossos pensamentos e estados mentais afetam, enquanto mentais, as nossas ações, e portanto o mundo fí-

\footnotetext{
${ }^{1}$ Recebido: 17-02-2012/Aprovado: 03-01-2013/Publicado on-line: 27-02-2013.

${ }^{2}$ Andrea Schimmenti é doutorando em Filosofia pela Universidade Federal da Bahia, Salvador, Bahia, Brasil.
} 
sico. Contudo, explicar como isto é possível tem se mostrado um problema muito difícil de ser resolvido no âmbito do fisicalismo não reducionista. No debate entre Davidson e Kim acerca da eficácia causal das propriedades mentais (as nossas crenças, desejos, intenções, etc.) no mundo físico, emergem pontos obscuros e dificuldades com relação à ideia, defendida por Davidson, de que a noção da eficácia do pensamento e da intenção no mundo material pode conviver com a liberdade da razão das leis da natureza. Neste sentido, a causalidade mental foi considerada por Kim uma ideia problemática e talvez incoerente, dados os compromissos básicos do fisicalismo não reducionista, que deixam as propriedades mentais causalmente e explicativamente impotentes, e, em geral, sem serventia alguma.

O fisicalismo davidsoniano se caracteriza por tomar posição contra a tese, geralmente aceita pelo fisicalismo reducionista, de que a explicação do comportamento e das ações humanas, através da referência a características psicológicas e a razões, é, fundamentalmente, explicação por subsunção a leis abrangentes, pois as relações causais entre o mental e o físico requerem o suporte de leis psico-físicas (HEMPEL 1975, 169).

Uma das expressões centrais e mais famosas da crítica davidsoniana à visão reducionista do tema do mental e da ação, é a tese do monismo anômalo, formulada a partir de três princípios, que, segundo Davidson, são coexistentes (DAVIDSON 1970b, 208):

1) Princípio de Interação Causal.

2) Princípio do Caráter Nomológico da Causalidade. 


\section{3) Princípio da Anomalia do Mental.}

O primeiro princípio, o Princípio de Interação Causal, afirma que pelo menos alguns eventos mentais ${ }^{3}$ interagem causalmente com os eventos físicos (IBID.). Por exemplo, as nossas crenças, desejos, intenções, esperanças, etc., causam as nossas ações, e as ações causam mudanças no mundo físico. Eventos no mundo físico, muitas vezes, são a causa da alteração das nossas crenças, desejos e intenções (IDEM 1994, 231). A interação causal, portanto, possui dois sentidos, pois pode ir do mental para o físico, e do físico para o mental. Davidson traz como exemplo de interação que vai do mental para o físico, o evento do afundamento do encouraçado Bismarck, em que vários eventos mentais tiveram um papel causal, como cálculos, julgamentos, crenças, ações intencionais. Para ilustrar o segundo caso, a interação causal como agindo no sentido que vai do físico para o mental, Davidson descreve uma situação em que uma pessoa crê que um barco está se aproximando. O que deve ter determinado tal crença é a percepção da pessoa de que um barco está se aproximando. Então, conclui Davidson, um barco que está se aproximando deve ter causado a crença de que está se aproximando um barco, ou seja, um evento físi-

\footnotetext{
${ }^{3}$ Davidson desenha uma ontologia mínima, em que tudo o que existe são eventos particulares (DAVIDSON 1969, 165). Um evento é um particular não repetível, localizável através de coordenadas espaço-temporais, como o nascimento ou a morte de alguém (IDEM 1967a, 137; 1970a, 181; 1970b, 209). Um evento não é necessariamente material, mesmo que haja a possibilidade de descrevê-lo de determinadas formas, por exemplo, como um evento físico ou mental. O que caracteriza fundamentalmente um evento mental não é ser privado, subjetivo, ou imaterial, mas é, simplesmente, possuir uma descrição no vocabulário mental, isto é, ser descrito através de um relato de atitude proposicional que inclui pelo menos um verbo mental, como "crer", "desejar", "esperar", etc. É exemplo disso: "Maria notou que chegou a hora de almoçar", "Paulo vê que o vento está mudando", "Carlos lembrou o nome da Camboja" (DAVIDSON 1994). Para Davidson, os estados mentais, como as crenças, os desejos, as esperanças, etc., são eventos (IDEM 1970b, 210). Um evento é físico, por sua vez, se é descrito através de termos e conceitos que se encontram no vocabulário das teorias da ciência da natureza.
} 
co foi a causa do evento mental (IDEM 1970b, 208).

O segundo princípio, o Principio do Caráter Nomológico da Causalidade, diz que todo enunciado singular verdadeiro de causalidade é suportado por uma lei estrita ${ }^{4}$ que coliga eventos dos tipos aos quais pertencem os eventos mencionados como causa e efeito (IBID., 223). Isto quer dizer que, onde há uma relação causal entre eventos, deve existir uma lei estrita, ou seja, os eventos que estão em relação de causa e efeito podem ser subsumidos debaixo de uma lei estrita que os coliga enquanto descritos como pertencentes a determinados tipos.

O terceiro princípio é o Princípio da Anomalia do Mental: não existem leis estritas em base às quais é possível prever e explicar os eventos mentais (IBID., 208), que não estão sujeitados às leis rigorosas que governam os eventos físicos. Este princípio concerne aos eventos descritos como mentais, já que os eventos são mentais somente enquanto descritos (IBID., 215). "Anomalia" significa, segundo Davidson, "insucesso em subsumir sob alguma lei" (DAVIDSON 1970b, 207). Os eventos mentais, como as percepções, as lembranças, as decisões e as ações, resistem à captura na rede nomológica da teoria física (IBID., 208). Não existem leis psicofísicas estritas, leis que conectam eventos mentais sob suas descrições mentais, com eventos

\footnotetext{
${ }^{4} \mathrm{O}$ que Davidson chama de "lei estrita" é algo que pode ser encontrado somente na física. É uma generalização determinística como a natureza, e trata o universo como um sistema fechado (DAVIDSON 1993, 191). Uma lei estrita deve ser precisa, não deve prever exceções, e pode ser tal somente se atinge seus conceitos no âmbito de uma teoria fechada e compreensiva (IDEM 1970b, 219). As leis estritas, no monismo anômalo, não cobrem os eventos descritos no vocabulário do mental. Segundo Davidson, não existem leis deste tipo nas ciências especiais, como a biologia, a geologia, a engenharia, a química, a genética, nem podem existir em psicologia. A maioria do conhecimento prático que os biólogos, os geólogos, os psicólogos usam para tentar explicar e predizer os eventos comuns, não envolve leis estritas, nem pode ser reduzido a leis estritas, mas concerne a meras generalizações que envolvem relações locais entre propriedades (IDEM 1993, 192-193).
} 
físicos sob suas descrições físicas (IDEM 1994, 231). Isto é, não existem leis que colocam em conexão as propriedades mentais e as propriedades físicas das quais são instâncias os eventos mentais e físicos que se encontram na relação causal.

A tese central de Davidson é que a contradição entre a anomalia do mental e seu papel causal no mundo natural é só aparente, pois os três princípios do monismo anômalo são as três premissas a partir das quais é possível inferir a verdade de uma versão de uma teoria da identidade, ou seja, de uma teoria que identifica pelo menos alguns eventos mentais com eventos físicos (IDEM 1970b, 208-209).

A demonstração da identidade é desenvolvida por Davidson da forma seguinte: supondo que $m$, um evento mental, causou $p$, um evento físico, é possível inferir que, sob alguma descrição, $m$ e $p$ instanciam uma lei estrita. Esta lei pode somente ser física, pois o terceiro princípio, o princípio da Anomalia do Mental, nega a existência de leis psicofísicas. Mas, se $m$ cai sob uma lei física, possui uma descrição física; isto é dizer que é um evento físico. Um argumento análogo vale quando um evento físico causa um evento mental. Então, todo evento mental que seja causalmente relacionado a um evento físico é um evento físico (IBID., 224).

2. A versão da teoria da identidade que Davidson sustenta, contra a tendência em ato na tradição fisicalista em construir teorias da identidade entre tipos de eventos, ou entre propriedades mentais e físicas, é uma teoria de identidade entre tokens, ocorrências de eventos, pois "é claro que se as 
únicas identidades são de tipos de eventos, a teoria da identidade pressupõe leis de correlação" (DAVIDSON 1970b, 212). Segundo Davidson, as formulações tradicionais do fisicalismo reducionista ${ }^{5}$ postulam, a priori, as condições de identidade de forma tal que qualquer identidade implique necessariamente uma lei de correlação (IBID. 213), e esta estratégia tem tido o resultado de associar a teoria da identidade ao reducionismo, ou seja, de associar a identidade ao caráter nomológico dos eventos mentais. As leis psicofísicas estritas, das quais Davidson nega a existência, desenvolvem a função de leis-ponte, ou seja, afirmam uma identidade, ou uma conexão de tipo forte, entre propriedades, ou tipos, mentais e físicos (IBID. 207).

Por exemplo, se "a crença que $A$ " é suposta idêntica ao estado cerebral $B$, é postulada a existência necessária de uma concomitância entre as ocorrências da "crença que $A$ " e as ocorrências do estado cerebral B. É, então, condição necessária para a identidade entre "a crença que A" e o estado cerebral $B$, que as expressões "crer que $A$ " e "encontrar-se no estado cerebral B" possuam a mesma extensão. Não seria possível, segundo o reducionismo, conceber alguma observação que confirme ou refute a identidade sem

\footnotetext{
${ }^{5}$ Ernst Nagel afirmou que uma redução é a explicação de uma teoria, ou de um conjunto de leis experimentais, estabelecidas numa área de indagação, através de uma teoria formulada para algum outro domínio (NAGEL 1961, 338). Uma redução é propriamente uma relação epistemológica entre teorias, ou seja, é uma forma de explicação, através da qual é afirmada a equivalência entre dois discursos teóricos, mostrando a derivabilidade de uma teoria de nível mais alto (por exemplo, a termodinâmica) de uma teoria de nível mais baixo (por exemplo, a mecânica estatística) (HORGAN 1994, 472). A redução num sentido ontológico, ou seja, a simplificação ontológica que obtemos quando afirmamos que não estamos lidando com duas propriedades distintas, mas com uma e uma única propriedade (por exemplo, o fato de que um gás esteja numa determinada temperatura é completamente explicado pelo movimento molecular), é geralmente vista como a consequência de uma redução epistemológica entre teorias que teve exito (KIM 1996, 214). A alegação de que termos de diferentes teorias remetem à mesma entidade inspirou a teoria da identidade entre tipos de eventos mentais e tipos de eventos físico-cerebrais (BAKER 1987, 8; EVNINE 1991, 61), que é expressão do ideal de redução da psicologia à ciência neurobiológica.
} 
confirmar ou refutar a correlação associada (IBID. 213). Para Davidson, pode haver identidade sem correlação, pois a identidade, assim como a causalidade, é uma relação entre eventos individuais (IDEM 1967b, 160). É crucial, no âmbito da teoria da identidade de Davidson, a distinção entre eventos particulares e tipos, ou gêneros, de eventos, pois somente esta é o que permite separar a identidade e a nomologicidade. A identidade de um particular evento mental, como "o meu desejo de que a Seleção ganhe a Copa", com um evento físico, como uma determinada conexão sináptica, não nos autoriza a inferir que todas as vezes que eu, ou outra pessoa, desejar que a Seleção ganhe a Copa, este desejo seja idêntico à mesma conexão sináptica, ou a uma conexão sináptica do mesmo tipo. Isto é um pouco como descrever o mesmo objeto, ao mesmo tempo, como uma gravata e um presente de Natal, sem que isto me autorize a dizer que todas as gravatas são presentes de Natal.

Davidson afirma não somente que a identidade das ocorrências não se encontra em contradição com o princípio da anomalia do mental, mas afirma algo mais forte: que a anomalia do mental é um dos princípios (conjuntamente ao princípio da interação causal e ao princípio do caráter nomológico da causalidade) dos quais se infere a identidade das ocorrências (IDEM 1970b, 223). A teoria da identidade de ocorrências é o alicerce da crítica de Davidson ao reducionismo, pois é justamente ela que, segundo Davidson, permite a reconciliação das três premissas. Através da identidade das ocorrências, o monismo anômalo pretende propor uma redução ontológica, e rejeitar uma redução no sentido epistemológico do termo, excluindo a redução conceitual (IDEM 1994, 231). No âmbito do problema da redução psicofísica, as leis-ponte fornecem as ligações cruciais 
entre propriedades mentais e físicas (IDEM 1970b, 207), e constituem por isto um fator crítico no seio do debate sobre a questão do mental no fisicalismo. $\mathrm{O}$ monismo anômalo, como é uma tese que defende a anomalia do mental, é uma tese contra a possibilidade do reducionismo no âmbito do problema da relação do mental com o mundo físico (KIM 1996, 218), e concerne uma questão importante de disputa no âmbito do fisicalismo, ou seja, a questão de como seria possível integrar no âmbito da visão naturalista do mundo os estados e eventos como crenças, desejos, intenções, etc., que são ordinariamente incluídos na rubrica do mental, e que parecem possuir um conteúdo semântico e intencional.

3. $\mathrm{O}$ argumento do monismo anômalo é aplicável somente para aquelas áreas da psicologia que fazem referência a atitudes proposicionais, como crença, desejo, e memória, ou usam conceitos logicamente conexos a estes, como o de percepção, de aprendizagem, de ação, sempre nos casos em que estes conceitos exibam um caráter intencional ${ }^{6}$ (DAVIDSON 1974, 240). O monismo anômalo está ligado ao projeto davidsoniano que consiste em construir uma teoria interpretativa da mente e da ação (IDEM 1970b, 225; 1974, 230; 1994, 231), e não pode se entendido fora do tema da explicação da ação intencional. Uma ação humana, para Davidson, não é algo que simplesmente acontece, pois

\footnotetext{
${ }^{6} \mathrm{O}$ mental, em Davidson, é intencional num sentido muito próximo ao de Brentano (DAVIDSON 1970b, 210 - 211), que caracteriza todo fenômeno psíquico pela transitividade, referência a um conteúdo, ou direção para um objeto que não deve ser entendido como efetivamente existente. Por exemplo, no amor algo é amado, no ódio algo é odiado, no desejo algo é desejado (BRENTANO 1997, 154-155).
} 
sua característica essencial é poder ser descrita em termos de intenção, isto é, como um ato que alguém executou intencionalmente (IDEM 1974, 229). Nós outorgamos cotidianamente crenças, desejos, intenções, etc., às pessoas, no processo através do qual tentamos explicar suas ações com base em determinados estados mentais que são supostos constituir as razões que levaram alguém a agir. A identidade de uma razão com um evento físico contribuiria a explicar, segundo Davidson, como os estados mentais que justificam racionalmente a ação podem ser considerados, ao mesmo tempo, os motivos da ação, isto é, uma espécie de causa, uma "causa racional" da ação (IDEM 1963, 12).

Os estados mentais são, sim, eventos particulares que fazem parte do fluxo causal da natureza, porém nem por isto uma explicação de uma ação intencional pode valer-se do instrumental teórico utilizado pela representação científico-natural do mundo. A explicação de uma ação é uma explicação racional-causal, que faz apelo a certas regularidades que admitem exceções e não permitem predizer as ações humanas. Trata-se, portanto, de uma explicação que opera numa moldura conceitual afastada do direito alcance das leis da física, e descreve a causa e o efeito, a razão e a ação, como aspectos do retrato de um agente humano (IDEM 1970b, 225). Uma explicação racional-causal é sempre uma explicação que vale para um caso específico. Ela é causal, mas não no mesmo sentido em que são causais as explicações da ciência física (IDEM 1973, 258). Segundo Davidson, as nossas explicações das ações intencionais estão fundadas na Ideia de que os eventos mentais mantêm relações causais, contudo, isto não pode ameaçar a tese de que estes mesmos eventos podem ser caracterizados como constituindo uma grande rede de 
atitudes proposicionais (crenças, desejos, esperanças, etc.), e podem, então, ser subsumidos pelos conceitos semânticos, intencionais, e normativos que caracterizam os contextos intensionais gerados pelos relatos de atitudes proposicionais (IDEM 1994, 231-232).

4. A principal razão da anomalia do mental e de sua irredutibilidade às leis da física repousa, para Davidson, na ideia de que não é possível tentar fornecer uma explicação racional das ações humanas, com base nas crenças, nos desejos e nas intenções, etc., dos agentes, sem pressupor princípios necessários e a priori, próprios do mental, isto é, o holismo e a normatividade, que são o grande critério ou medida do mental, e são constitutivos do ideal de coerência e racionalidade que deve governar o processo interpretativo (DAVIDSON 1970b, 220-221; 1994, 232). O mental pode ser descrito somente em termos holísticos: podemos atribuir crenças, desejos, intenções, etc., a alguém, somente pressupondo nele outras crenças, desejos, intenções, etc. (IDEM 1970b, 221; 1973, 255; 1994, 231-232). As relações entre os estados mentais são essencialmente lógicas, e isto impõe uma limitação normativa no contexto da correta atribuição de um estado mental, no sentido de que o padrão de atitudes num indivíduo deve exibir um grande grau de coerência (IDEM 1994, 232). No contexto da explicação de uma ação, porém, os princípios normativos da racionalidade humana não podem ser aplicados de forma absoluta, como na lógica, pois operam sempre sobre grupos de estados mentais que podem variar a depender das circunstâncias. A explicação de uma ação intencional, por poder considerar 
somente os estados mentais que podem intervir numa determinada situação, é uma explicação aproximativa e imprecisa, que é qualificada por clausulas de proteção de falhas como são as clausulas chamadas de "ceteris paribus", ou "na ausência de condições que interfiram" (KIM 1996, 143).

Se existissem leis ponte psico-físicas, segundo Davidson, não seria mais possível supor que as propriedades mentais são caracterizadas pelos conceitos holísticos e normativos que caracterizam as atitudes proposicionais, e, portanto, os estados mentais seriam atribuídos às pessoas em base, por exemplo, às leis da neurobiologia (DAVIDSON 1973, 248). Há aqui a Ideia de um contraste crucial entre a organização interna do espaço das explicações racionais e a organização interna do espaço das explicações científico-naturais (McDOWELL 2005, 108).

5. A crítica de Kim ao monismo anômalo tem como alvo a ideia central da tese de Davidson, isto é, a ideia de que a eficácia causal dos eventos mentais no mundo físico, e seu caráter anômalo, são assunções que não estão em contradição (DAVIDSON 1970b, 207). Segundo Kim, o monismo anômalo afirma que o mental é um epifenômeno, ou seja, não possui eficácia causal no mundo físico, pois não existem, no monismo anômalo, relações significativas entre os tipos ou as propriedades mentais e os tipos ou as propriedades físicas (KIM 1993, 269-270; 2003 125-126). No monismo anômalo, sustenta Kim, o mental não opera causalmente, pois no monismo anômalo os eventos são causas ou efeitos somente na medida em que instanciam 
leis físicas, então a anomalia do mental implica que os tipos ou as propriedades mentais de um evento não produzem alguma diferença de caráter causal (KIM 1993, 269; 2003, 125). Para Kim, o argumento do monismo anômalo alega em seu segundo princípio, que qualquer relação causal que envolve um evento mental e um evento físico se sustenta somente porque uma lei estrita da física subsume os dois eventos debaixo de tipos ou descrições físicas. Sendo assim, eventos mentais individuais têm eficácia causal somente enquanto instanciam tipos físicos, e caem sob leis estritas, ou seja, sob leis físicas. Kim acredita que, no monismo anômalo, é somente sob sua descrição física que um evento mental pode ser visto entrar numa relação causal com um evento físico:

os eventos mentais entram em relações causais, na visão de Davidson, mas as leis que suportam estas relações causais são leis físicas, leis que conectam tipos físicos com tipos físicos. (KIM 2003, 125).

Supor que mudando as propriedades mentais de um evento poderiam mudar suas propriedades físicas, e com isto suas relações causais, é supor que a anomalia psicofísica, uma crença fundamental do monista anômalo, é falsa (IDEM 1993, 270). Segundo Kim, sendo que o terceiro princípio do monismo anômalo estabelece a ausência de leis psicofísicas estritas, o fato de que um evento mental é um evento mental, ou seja, o fato de que um evento mental individual instancia o tipo de evento mental que instancia, não têm alguma influência causal (KIM 1993, 270; 2003, 125-126).

Kim conclui que, no monismo anômalo, a estrutura causal do mundo é totalmente determinada pelos tipos e propriedades físicos instanciados pelos eventos do mundo 
(IDEM 2003, 132): o monismo anômalo implica que, se redistribuíssemos as propriedades mentais aleatoriamente sobre seus eventos, ou se até removêssemos inteiramente o mental do mundo, não chegaríamos a comprometer alguma relação singular de causalidade (IDEM 1993, 269). Para Kim, a anomalia do mental e a eficácia causal do mental não podem coexistir: a anomalia implica a ineficácia causal do mental no mundo físico. A ideia central desta alegação, comumente aceita pelo fisicalismo reducionista, é a de que o mental é causalmente eficaz somente se os eventos mentais são causas em virtude de suas propriedades: é em termos das propriedades e de suas inter-relações que nós damos sentido a conceitos como o de lei, de causalidade, de explicação, e de dependência.

6. Davidson, reconhecendo a grande importância da questão que Kim levanta, alega que, se o mental é causalmente inerte, como Kim afirma, então a primeira premissa do monismo anômalo é falsa, e as três premissas são inconsistentes entre si (DAVIDSON 2005a, 185). Davidson opõe a Kim uma objeção: a afirmação de que, no monismo anômalo, os eventos são causas somente enquanto instanciam leis físicas, é surpreendente, pois é algo que ele jamais sustentou (IBID., 188). Em seus artigos, Davidson tem incessantemente afirmado que não faz sentido dizer que um evento é uma causa "enquanto algo" (IDEM 1967b, 160). Na ontologia de Davidson os eventos são particulares não abstratos, e as relações causais são relações binárias extensionais entre tais eventos. Tomar um evento extensionalmente, quer dizer tomá-lo como a extensão da expressão lingüística que o 
descreve, ou seja, considerá-lo como aquele objeto particular ao qual a expressão lingüística se aplica. Um conceito como o de "causa enquanto" tornaria a causalidade uma relação entre mais de duas entidades. Portanto, não faz sentido, para Davidson, dizer que um evento $m$ causou um evento $f$ enquanto instancia a lei $l$ (DAVIDSON 2005a, 188-189). Para Davidson, "o princípio de interação causal resulta cego com relação à dicotomia mental/físico" (DAVIDSON 1970b, 215), ou seja, o primeiro dos três princípios do argumento do monismo anômalo trata os eventos em extensão, independentemente da questão de suas descrições. A causalidade, para Davidson, é uma relação entre eventos singulares, tomados extensionalmente, e neste sentido concerne a relações entre eventos individuais, não importa como descritos. Os eventos, portanto, não entram numa relação causal em virtude de ser descritos como físicos ou como mentais (IDEM 2005a, 189).

Por exemplo, qualificar a incursão militar em Panamá como "a operação justa causa" não altera as consequências do evento (IBID., 190). Não podemos dizer que um evento causou outro enquanto descrito, pois as descrições de um evento não mudam o que este causa (IBID., 189). Se a relação causal é inerente à particularidade e à extensionalidade dos eventos, então o modo como os eventos são descritos, e as propriedades que usamos para caracterizá-los e individuálos, não podem afetar o que eles causam. Neste contexto deve ser compreendido o segundo princípio do monismo anômalo, o princípio do caráter nomológico da causalidade:

O principio do caráter nomológico da causalidade deve ser lido com atenção, pois afirma que quando os eventos estão em relação de causa e efeito, possuem descrições que exemplificam uma lei, mas não 
diz que todo enunciado singular verdadeiro de causalidade exemplifique uma lei. (DAVIDSON 1970b, 215).

Um exemplo de um enunciado singular de causalidade é "a erupção do Vesúvio em 79.a.d. causou a destruição de Pompéia” (DAVIDSON 2005b, 210). Um enunciado singular de causalidade é definido por Davidson como um enunciado que contém dois termos singulares (nomes, ou descrições definidas, que se referem a eventos), coligados por alguma forma do verbo "causar" ou de verbos que possuem um significado parecido, como "produzir", "resultar em", "ter como consequência”, etc. (IBID., 202-203).

Segundo Davidson, quem acredita que um enunciado singular de causalidade implica a existência de uma lei estrita que o suporta, deve de alguma forma indicar alguma lei particular que regula o caso em questão. Porém, fazer isto é problemático. Os enunciados singulares de causalidade são extensionais: seu valor de verdade não muda ao substituir ao nome ou à descrição de um evento outro nome ou descrição do mesmo evento. Assim, se Sócrates foi o marido de Xantipa, e "o beber a cicuta por parte de Socrates causou a morte de Sócrates", segue-se que "o beber a cicuta por parte de Sócrates causou a morte do marido de Xantipa”. Porém, dadas as possibilidades inesgotáveis que temos para redescrevermos os eventos em termos não equivalentes, muitas vezes não temos pistas, através dos conceitos que usamos para definir um evento, para chegar a caracterizar uma apropriada lei que governa o caso em questão (IBID. 202). Segue-se, para Davidson, que o princípio do caráter nomológico da causalidade deve ser lido no seguinte sentido: se um enunciado singular de causalidade é verdadeiro, há uma lei que governa o caso em questão, e nós podemos saber isto sem saber qual seja esta lei (IBID.). Esta leitura do prin- 
cípio do caráter nomológico da causalidade é um dos pilares do fisicalismo não reducionista de Davidson, pois, segundo ele, permite separar duas questões que nem sempre foram adequadamente diferenciadas pela tradição empirista humeana, isto é, a questão da explicação causal em termos de regularidades nomológicas, e a ulterior questão da causação como relação entre eventos (IDEM 1967b, 160). A causalidade é uma relação entre eventos individuais, não importa como descritos, mas os eventos podem instanciar leis, e portanto ser explicados ou previstos na luz de leis, somente se são descritos de uma ou de outra forma (IDEM 1970b, 215; 2005a, 199). Numa explicação causal, a dependência causal é armada segundo a forma em que as coisas estão descritas.

Assim, a falência das leis psico-físicas não tem alguma consequência sobre a questão se os eventos mentais e físicos estão causalmente relacionados. Mesmo se não existissem leis psico-físicas de qualquer tipo (estritas ou não estritas) isto não provaria a ineficácia causal do mental (IDEM 2005a, 194).

7. Para Kim, a extensionalidade da relação causal não é aqui uma questão central (KIM 2003, 128). Isto é, dizer que a relação causal entre eventos é uma relação que concerne aos eventos tomados extensionalmente, não é suficiente para podermos afirmar que existe uma eficácia causal do mental, pois o que está em questão é a eficácia causal das propriedades ou dos tipos mentais dos quais são instâncias os eventos que se encontram na relação causal. A eficácia causal do mental deve remeter, segundo Kim, à existência 
de leis psico-físicas.

Kim afirma que, além disso, Davidson concorda tacitamente com a acusação de epifenomenalismo que ele mesmo lhe dirigiu em seu escrito The myth of nonreductive materialism (KIM 1993), pois aceita a alegação de que, para podermos dizer que há eficácia causal, não é suficiente a presença da mera relação de causalidade que há entre os eventos tomados extensionalmente (KIM 2003, 127). Davidson admite que, para que se possa dizer que há uma eficácia causal do mental, é fundamental mostrar que existe uma relevância causal das propriedades mentais. Por esta razão Davidson, em Thinking Causes (DAVIDSON 2005a), lança mão de uma segunda estratégia argumentativa, como um "plano B", para tentar mostrar que no monismo anômalo, afinal, as propriedades mentais não são causalmente ineficazes. A segunda estratégia consiste em acrescentar duas outras teses à tese que atribui um papel central à extensionalidade dos eventos que aparecem na relação causal. São estas: a tese da sobreveniência das propriedades mentais sobre as propriedades físicas, e a tese que afirma a existência de generalizações não estritas que podem ser expressas em termos mentais (KIM 2003, 127).

8. A tese da sobreveniência ${ }^{7}$ do mental sobre o físico, explorada mais amplamente por Davidson em Thinking Causes (DAVISON 2005a, 186) no contexto do debate com Kim, foi por ele introduzida muito brevemente em Mental Events

\footnotetext{
${ }^{7}$ Não pretendo, neste artigo, aprofundar o tema da sobreveniência, que em Davidson se origina na filosofia da moral (DAVIDSON 1993, 186). Sobre a questão, podem ser consultados McLaughlin (1985), Kim (1993b), e Caorsi (2005).
} 
(IDEM 1970b, 214), para suportar seu argumento do monismo anômalo. A sobreveniência expressa a Ideia de que dois eventos que são idênticos em suas propriedades físicas devem ser idênticos em suas propriedades mentais, isto é, não podem existir eventos distintos pelas suas propriedades mentais que não podem ser distintos pelas propriedades físicas. Portanto, uma mudança nas propriedades mentais de um evento é sempre acompanhada por uma mudança nas suas propriedades físicas (IDEM 1993, 190). A sobreveniência significa dependência do mental com respeito ao físico, ou seja, o caráter mental de um evento é dependente de, ou é determinado por, seu caráter físico (KIM 2003, 129). No sentido de Davidson, esta Ideia de dependência implica que as propriedades mentais fazem uma diferença para as relações causais de um evento, pois elas têm importância para as propriedades físicas, e as propriedades físicas têm importância para as relações causais (DAVIDSON 1993, 197). Ou seja, o fato de que um evento cai sob um tipo mental faz uma diferença causal com relação a seu tipo físico: supondo, então, que um evento instancie um determinado tipo mental, se o evento não fosse daquele determinado tipo mental, não poderia ser o tipo de evento físico que é (KIM 2003, 130).

Segundo Davidson, a sua tese da sobreveniência, que deve ser entendida num sentido fraco, implicando meramente generalizações em sentido não estrito (DAVIDSON 1970b, 214; 1993, 196-197), esclarece o fato de que as três premissas do monismo anômalo são consistentes (IDEM 1993, 186), por implicar monismo, mas não redução, nem a redução nomológica através de leis estritas (leis-ponte psicofísicas), nem a redução através de definições de conceitos mentais em termos de conceitos físicos. $O$ fato de que uma 
mudança nas propriedades mentais $m$ de um determinado evento $x$ é sempre acompanhada por uma mudança nas suas propriedades físicas $p$, não quer dizer que, em outro evento $y$, as mesmas propriedades físicas mudem com as mesmas propriedades mentais. Somente esta condição implicaria a existência de uma lei (IBID. 189).

Para Kim, a tarefa que o conceito de sobreveniência fraca defendido por Davidson pode, no máximo, realizar, é a de ajudar a defender não a eficácia causal, mas a mera relevância causal das propriedades mentais de um evento (KIM 2003, 130): os sintomas de uma doença, por exemplo, podem ser causalmente relevantes para o desenvolvimento ulterior da patologia, mas isto não quer dizer que eles possuem eficácia causal no sentido de determinar o decurso da doença. Kim acredita que, sendo que o conceito de sobreveniência de Davidson não ameaça a anomalia do mental (pois nega a existência de leis estritas psicofísicas), não pode garantir a eficácia causal das propriedades e dos tipos mentais. Portanto, a sobreveniência não é consistente com o monismo anômalo, pois viola seu primeiro princípio (IBID. 131-132).

9. Para Davidson, a existência de meras generalizações psicofísicas não estritas, que enunciam relações locais entre propriedades mentais e físicas, suporta muito bem a eficácia causal dos eventos mentais. Por esta razão, ele pensa que o conceito de sobreveniência fraca que ele introduz não poderia ser inconsistente com o monismo anômalo (DAVIDSON 1993, 197). Davidson diz que ele nunca negou a existência de regularidades, ou generalizações psicofí- 
sicas não estritas (IBID. 192): por exemplo, o enunciado "o desconcertar-se de Mário ontem na festa foi causa de seu enrubescer" é suportado pela lei não estrita que conecta o tipo mental "desconcerto" com o tipo físico "enrubescimento". Isto significa que o evento mental e o evento físico estão relacionados como causa e efeito enquanto instanciam tipos tomados em consideração numa lei não estrita (KIM 2003, 128).

Estas generalizações psicofísicas não estritas, que Davidson menciona em Thinking Causes, foram por ele mencionadas também em Mental Events. Porém, em Mental Events, ele afirma que se trata de generalizações não nomológicas $^{8}$ (not lawlike), ou seja, generalizações que não possuem o caráter de leis (DAVIDSON 1970b, 216). Em Thinking Causes, Davidson afirma que ele não vai objetar se alguém chamar de leis estas generalizações psicofísicas não estritas (IDEM 1993, 192). No contexto do debate com

\footnotetext{
${ }^{8}$ Davidson afirma laconicamente que um enunciado é nomológico (lawlike) se e somente se é uma generalização que suporta teses contrafatuais e subjuntivas, e que é confirmável pelas suas ocorrências (como, por exemplo, o enunciado "todas as esmeraldas são verdes") (DAVIDSON 1970b, 217-218; 2005b, 206). O que Davidson chama de lei, é um enunciado nomológico verdadeiro quantificado universalmente (IDEM 2005b, 203). As leis podem ser condicionais universalizados, bicondicionais universalizados, ou podem ter forma estatística (McLAUGHLIN 1985, 333). A nomologicidade admite graus (DAVIDSON 1970b, 217): um enunciado geral pode, por exemplo, colocar em relação duas propriedades $m$ e $p$, sendo que $m$ pode ser somente necessária, ou somente suficiente para p. Uma generalização nomológica pode ser considerada ainda mais fraca quando $m$ não é nem necessária, nem suficiente, para p. (KIM 1985, 379). Existem enunciados que expressam generalizações verdadeiras que relacionam o mental e o físico, e possuem a forma lógica de uma lei, mas não podem ser considerados nomológicos (DAVIDSON 1970b, 216). Enunciados como estes são generalizações que valem ceteris paribus. Seguindo um exemplo oferecido por Kim, dado um determinado domínio de objetos, chamado de $U$, o enunciado "todos os objetos vermelhos em U são redondos", é uma mera generalização cheia de exceções, que é verdadeira só acidentalmente. Este enunciado expressa uma relação de coextensividade que não é uma coextensividade nomológica: não suporta um contrafatual, como, por exemplo, "se as bananas fossem vermelhas, seriam redondas"; nem é confirmável pelas suas instâncias, pois a única via para a sua confirmação seria um exame exaustivo e tedioso de todos os objetos no domínio. O mesmo vale para um enunciado como "todas as pessoas com a propriedade mental $\mathrm{m}$ possuem a propriedade física p” (KIM 1985, 373).
} 
Kim, Davidson confere a estas generalizações não estritas um caráter nomológico.

Davidson tenta defender a ideia de que há causalidade mental sem redução: ele afirma que, se é suficiente a existência de leis não estritas, então não há reducionismo (IBID., 198). Há exemplos de generalizações não estritas que podem ser encontradas em geologia: "As montanhas estão aptas a ter neve sobre elas: por isto, o monte Everest tem neve em cima dele", ou "Um rio com sua correnteza erode seu leito, a não ser que, por exemplo, o tempo mude e o rio seque" (DAVIDSON 1993, 193).

Kim acredita que o apelo às generalizações não estritas é problemático para Davidson, pois torna inútil o princípio do caráter nomológico da causalidade: qual é a razão do princípio do caráter nomológico da causalidade, o princípio que requer que leis estritas sejam garantias da relação causal (KIM 2003, 128), se as generalizações não estritas podem fazer este trabalho?

Kim parece não levar em conta que, para Davidson, a relação causal não precisa ser garantida por leis, por ser uma relação entre eventos tomados em extensão. Porém, a crítica de Kim atinge o alvo no sentido de que desperta a atenção na direção do seguinte ponto obscuro na articulação de Davidson: se a existência da relação de causalidade entre eventos mentais e eventos físicos tomados em extensão é suficiente para garantir a eficácia causal do mental, qual é a função das generalizações não estritas?

No monismo anômalo, não parece que se possa dizer que a função de garantia da relação causal seja própria das generalizações não estritas, e o mesmo parece valer para as propriedades mentais. Davidson não diz que as propriedades mentais funcionam como as garantias da relação causal. 
Com relação a este tema, Davidson afirma que "as propriedades mentais são causalmente eficazes se fazem uma diferença para o que os eventos individuais causam" (DAVIDSON 1993, 198), e que a sobreveniência assegura esta "diferença" (IBID.). Acredito que a sua afirmação, um pouco obscura, não parece trazer maior luz sobre a seguinte questão: a eficácia causal é imputável, afinal, aos eventos tomados extensionalmente, ou às suas propriedades? No mesmo movimento em que Davidson parece atribuir às propriedades mentais uma eficácia causal (enquanto afirma que as propriedades mentais fazem uma diferença com relação à causação), ele afirma também que o que causa, o que faz a função de causar, são os eventos individuais.

10. Davidson reconhece, afinal, que o monismo anômalo é, sim, consistente com a tese epifenomenalista de que o mental não causa nada enquanto "mental", isto é, com a tese de que as propriedades mentais dos eventos não são causalmente eficazes (DAVIDSON 1993, 196). Porém, segundo ele, esta consistência não é suficiente para desacreditar o monismo anômalo, pois dela não segue que o monismo anômalo implica a inércia causal do mental: são os epifenomenalistas, afirma Davidson, que precisam mostrar que o monismo anômalo implica a ineficácia causal das propriedades mentais. Uma via para conseguir esta demonstração, ele afirma, seria mostrar que o monismo anômalo é inconsistente com a sobreveniência. A refutação do monismo anômalo consistiria em mostrar não que o monismo anômalo é inconsistente, mas bem que o monismo anômalo é inconsistente com a sobreveniência, e então com a dúplice suposição de 
que as propriedades mentais de um evento fazem uma diferença para suas relações causais, e de que, ao mesmo tempo, não existem leis estritas para o mental (IBID. 196-197). Mas, segundo Davidson, não haveria como demonstrar esta inconsistência.

Davidson tenta nos ajudar a compreender, através de um exemplo, como é que as propriedades mentais possuem uma eficácia causal. Ele imagina uma situação em que Magalhães, o navegador, nota um rochedo no mar, dá ordens para sua tripulação, e estes eventos causam o desvio do navio. $O$ notar de Magalhães é um evento mental, tem propriedades mentais, e é causalmente eficaz. Este evento é também um evento físico, uma ativação de uma conexão neural no cérebro de Magalhães, suposta descritível no vocabulário da física. Sendo que os predicados usados para descrever os eventos mentais não são redutíveis aos predicados da física, tudo isto, segundo Davidson, é coerente com o monismo anômalo (IBID. 195).

Contudo, como afirmar que o evento que Davidson chama o "notar" de Magalhães é causalmente eficaz em virtude da sua descrição como mental, ou seja, em virtude de seu ter propriedades mentais? Este é um ponto central. Davidson, porém, não esclarece qual seria o peso da "diferença" que as propriedades mentais fazem na produção da eficácia causal dos eventos. Acredito que, em falta de uma resposta para esta pergunta, não se pode afirmar que o monismo anômalo pode suportar a alegação da eficácia causal do "mental".

A posição sustentada por Davidson em Mental Events (IDEM 1970b, 216), onde ele não confere caráter nomológico às generalizações psicofísicas não estritas (por serem elas generalizações que valem ceteris paribus), dá lugar a uma 
leitura forte do monismo anômalo (ROSENBERG 1985, 402; ANTONY 1994, 224 - 225). Segundo a leitura forte, as propriedades mentais não podem comparecer em alguma lei, seja ela estrita ou não estrita. Isto é, nenhum predicado mental pode fazer parte de algum enunciado nomológico, as relações causais entre eventos mentais e físicos não podem ser suportadas por relações nomológicas entre propriedades. Neste sentido, desde um ponto de vista naturalista e fisicalista do mental, a leitura forte do monismo anômalo se encontra questionada.

A referência de Davidson à existência de generalizações psicofísicas não estritas, que possuiriam um caráter nomológico, e ajudariam a mostrar que as propriedades mentais têm uma eficácia causal, foi considerada uma leitura fraca do monismo anômalo (ROSENBERG 1985, 402; ANTONY 1994, 224-225). Este tipo de leitura, também, não é imune às críticas, à medida que Davidson não caracteriza de forma precisa estas generalizações psicofísicas não estritas com caráter de lei, e portanto, não parece poder oferecer uma demonstração realmente convincente de que a existência de tais generalizações confere eficácia causal às propriedades mentais. Certamente, esta questão deveria ser aprofundada através de uma indagação sobre a questão da sobreveniência, à qual Davidson delega, afinal, a tarefa da defesa da eficácia causal das propriedades mentais (DAVIDSON 1993, 198).

Há hoje consenso geral de que o que mais encontramos na ciência são leis estatísticas, leis cheias de exceções, isto é, leis não estritas, ou, como no caso da física quântica, leis indeterminísticas (ANTONY 1994, 226; RORTY 1999, 582 ), e isto pode levar a crer que uma leitura fraca do monismo anômalo, a qual nega a existência somente das leis 
psicofísicas estritas, mas aceita a existência de leis psicofísicas não estritas, não caracteriza de forma suficientemente clara o âmbito dos conceitos mentais com respeito ao âmbito dos conceitos tratados por ciências empíricas como a química ou a biologia, e até a própria física. Poderíamos então perguntar qual seria a função dos princípios do holismo e da normatividade, princípios necessários, e estabelecidos a priori através de uma simples análise conceitual, que para Davidson são constitutivos do mental. São legitimas, neste sentido, questões como as seguintes: de que forma estes princípios poderiam realmente sustentar a afirmação da inexistência de leis estritas que governam o mental, se eles oferecem de fato uma proteção contra o reducionismo, e qual seria sua capacidade para resolver problemas teóricos que surgem das ciências empíricas.

Não seria então implausível caracterizar o monismo anômalo como uma solução dualista de estilo kantiano (KIM 1985, 385). Esta opinião é respaldada, por exemplo, por críticos como Michael Antony (ANTONY 2003, 2), que afirma ser inválido o argumento através do qual Davidson tenta, a partir do princípio da anomalia do mental, demonstrar o monismo (a identidade das ocorrências) (DAVIDSON 1970b, 224).

11. Ao tentar mostrar a imprecisão da leitura de Kim, Davidson expõe a sua própria posição a um tipo de crítica diferente daquela feita por Kim. Davidson admite que não haja como não reconhecer que, se um evento pode ser chamado de "mental", isto depende inteiramente de como o evento pode ser descrito (DAVIDSON 1993, 190), pois 
"os eventos são mentais somente enquanto descritos", e "um evento é mental se e somente se possui uma descrição mental” (DAVIDSON 1970b, 211). Isto, porém, conjuntamente à outra afirmação de Davidson de que a causalidade é uma relação que concerne aos eventos extensionalmente, poderia nos levar a pensar que o fato de que um evento é um evento mental, isto é, pode ser descrito através de relatos de atitudes proposicionais que incluem verbos mentais, como crer, desejar, etc. (IBID. 210), não pode fazer nenhuma diferença quanto às causas e aos efeitos daquele evento. Pois, o que significa dizer que um evento "mental" é eficaz causalmente? Dizendo isto, estamos atribuindo eficácia causal ao evento mesmo, ou à sua descrição como mental? Supomos, por exemplo, estar descrevendo um evento chamado de $x$ como "um evento mental", pelo enunciado " $x$ é um evento mental". Ao afirmarmos "o evento mental $x$ possui eficácia causal", nós estamos atribuindo eficácia causal à descrição de $x$, ou a $x$ considerado intrinsecamente?

Nós podemos afirmar que o que possui eficácia causal é o evento mental $x$, e não a sua descrição, somente se o enunciado " $x$ é um evento mental" remete a um contexto extensional. Se o contexto não é extensional, cabe a suspeita de que, ao dizermos que x possui eficácia causal, estamos na verdade atribuindo eficácia causal a uma descrição. Se assim fosse, poderiamos então perguntar se os eventos mentais existem realmente.

M. Johnston e J. McLaughlin acenam a esta questão, com opiniões contrastantes. Segundo McLaughlin (McLAUGHLIN 1985, 336), a definição de evento mental fornecida por Davidson não pretende significar que um evento é mental somente debaixo de uma descrição ou 
somente quando descrito como mental. Isto porque a posição ocupada por a no enunciado " $a$ satisfaz o enunciado mental aberto ' $x$ é $m$ '” é extensional; e igualmente com relação à posição ocupada por $a$ no enunciado "a satisfaz o enunciado físico aberto ' $x$ é $p$ "” (IBID.).

Segundo Johnston (JOHNSTON 1985, 420), o contexto "x é um evento mental" não pode ser extensional, pois, se assim fosse, a tríade " $M$ é um evento mental", "P não é um evento mental", " $M=P$ " seria inconsistente. Portanto, " $x$ é um evento mental", é um contexto intensional, assim como " $x$ é um evento físico" (IBID.). Johnston conclui que a teoria da identidade das ocorrências expressa um fato lingüístico, ou seja, que todo evento com alguma descrição mental tem alguma descrição física.

No contexto do debate com Kim, Davidson não aprofunda este problema, e afirma somente que não faz algum sentido supor que descrevê-lo no vocabulário mental poderia privar o evento de sua eficácia causal (DAVIDSON 1993, 195). Acredito que a extensionalidade do contexto deveria ser demonstrada, e não pressuposta, no âmbito da tese do monismo anômalo. Em falta de uma demonstração neste sentido, eu poderia crer que, ao afirmar que um evento "mental" possui eficácia causal, estou na verdade atribuindo eficácia causal a uma mera descrição, que pode não existir na realidade do mundo.

Também, o tema da individuação dos eventos mentais como particulares não repetíveis, como os objetos extensionais aos quais a expressão linguística se refere, constitui um problema não fácil, que requer ulterior indagação. Davidson não parece encontrar um critério plenamente satisfatório para individuar os eventos. Ele 
reconheceu que, como uma montanha é identificada univocamente fornecendo a latitude e a longitude de seu pico mais alto, mas na verdade ela ocupa mais de um único ponto no espaço, assim, de uma forma análoga, e com não maior precisão, identificamos um evento mental (IDEM 1969, 176). No processo de individuação de um evento mental, Davidson é levado inevitavelmente a utilizar descrições construídas através de relatos de atitudes proposicionais, que ajudam a selecionar e demarcar o evento. Podemos remeter a um mesmo evento particular através de vários termos singulares (IDEM 1967b, 160), que, além de nomes, podem ser descrições definidas (IDEM 1969, 164). Isto torna possível uma leitura que confere caráter linguístico à noção davidsoniana de evento mental, leitura que pode levar a caracterizar o monismo anômalo como uma solução não muito distante do eliminativismo, pois podemos pensar que os eventos mentais, aos quais os enunciados mentais parecem se referir em sua forma lógica e gramatical, podem, de fato, não existir.

12. A teoria da identidade das ocorrências, alicerce na tese do monismo anômalo, não pode ter o papel de permitir que uma relação de causalidade entre um evento mental e um evento físico possa ser subsumida por uma lei psicofísica, isto é, por uma generalização que estabelece uma regularidade nomológica que governa a relação entre as propriedades mentais e as propriedades físicas. Neste sentido, a teoria da identidade das ocorrências não permite um elo suficientemente forte entre o mental e o físico, para que sejam garantidas as exigências do naturalismo fisicalista em 
termos da explicação causal. Isto leva a crer que a teoria davidsoniana da ação, que remete às "causas mentais" para a caracterização da ação intencional, não possui os requisitos explicativos que uma teoria fisicalista da ação deve possuir. O problema é que, para termos uma explicação causal, não é suficiente citar uma causa, mas é preciso compreender o papel jogado, na produção do efeito físico, pelas propriedades mentais em termos das propriedades físicas a elas conexas.

A tese da anomalia do mental e a tese da eficácia causal do mental não são facilmente harmonizáveis no âmbito de uma visão fisicalista do mundo. Parece problemático justificar o papel causal que o mental teria no mundo físico sem admitir a existência de leis psicofísicas que possam suportar as relações de causalidade entre os eventos mentais e os eventos físicos. Estou inclinado a acreditar, com Kim, que o monismo anômalo é uma tese epifenomenalista, e que, no monismo anômalo, a anomalia do mental e a eficácia causal do mental são teses incompatíveis. Isto significa dizer que o monismo anômalo não pode suportar completamente a ideia inspiradora do projeto de Davidson, isto é, a ideia de que a eficácia do pensamento e da intenção no mundo material pode conviver com a liberdade da razão com relação às leis naturais (DAVIDSON 1970b, 224).

Abstract: this paper focuses some aspects of a debate which took place between Donald Davidson and Jaegwon Kim, about the problem of causal efficacy of mental properties in the physical world. The most famous expression of davidsonian non reductive physicalism, the argument of Anomalous Monism, was criticized by Kim, because it tries to harmonize two allegations that can't coexist in a physicalist thesis, and have to be considered as incompatible from a physicalist point of view. The first of these allegations is the Anomaly of the Mental, which defines the mental as autonomous from the system of laws that rule physical phenomena. The second allegation is that mental events and human actions are part of causal flow of natural events. Anomalous Monism seems to be an epiphenomenalist thesis, be- 
cause, in Anomalous Monism, anomaly of the mental rules out causal efficacy of the mental in physical world.

Keywords: mind; physicalism; mental causality; anomalous monism.

\section{REFERÊNCIAS}

ANTONY, L. The Inadequacy Of Anomalous Monism As A Realist Theory Of Mind. Language, Mind And Epistemology. Dordrecht/Boston/London: Kluwer Academic Publishers, 1994, p 223-253.

ANTONY, M. Davidson's Argument For Monism. Dordrecht, Kluwer Academic Publishers. Synthese 135: 1-12, 2003.

BAKER, L. R. Saving Belief. A critique of Physicalism. Princeton, Princeton University Press, 1987, xii, 177 p

BRENTANO, F. La Psicologia dal punto di vista empirico I, trad. italiana R. L. Dappiano. Roma-Bari, Laterza, 1874 [1997], xxviii + 245 p

CAORSI, C. Sobreveniência e monismo anômalo. In:_. J. SMITH, P. e SILVA FILHO, W. (orgs.) Davidson e a Filosofia, Loyola, São Paulo, 2005, p 67-79.

DAVIDSON, D. Actions, Reasons and Causes. In: . Essays on Actions and Events. Oxford: Oxford University Press, [1980] 1963, p 3-19.

. The Logical Form of Action Sentences. In:

Essays on Actions and Events. Oxford: Oxford University Press, [1980] 1967a, p 105-148.

. Causal Relations. In: . Essays on Actions and Events. Oxford: Oxford University Press, [1980] 1967b, 
p149-162.

. The Individuation of Events. In: . Essays on Actions and Events. Oxford: Oxford University Press, [1980] 1969, p163-180.

. Events as Particulars. In: . Essays on Actions

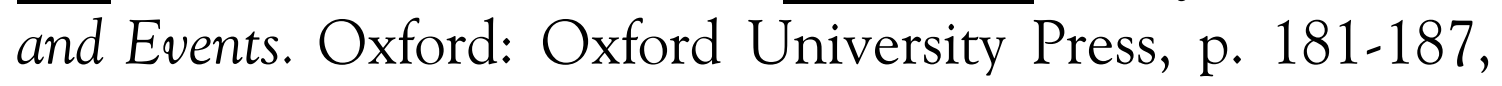
1970a.

. Mental Events. In: . Essays on Actions and Events. Oxford: Oxford University Press, 1980, p207- 227, 1970b.

. The Material Mind. In: . Essays on Actions and Events. Oxford: Oxford University Press, [1980] 1973, p245- 259.

. Psychology as Philosophy. In: . Essays on Actions and Events. Oxford: Oxford University Press, [1980] 1974, p 229-244.

. Thinking Causes. In: . Truth, Language, and History, Oxford: Clarendon Press, 2005a, p185-200.

. Laws and Causes. In: . Truth, Language, and History, Oxford: Clarendon Press, 2005b, p201-219.

. Donald Davidson. In: . GUTTENPLAN, S. (ed.) A Companion to the Philosophy of Mind. Oxford: Blackwell, 1994, p 231-236.

EVNINE, S. Donald Davidson. Cambridge: Polity Press, 1991, $198 \mathrm{p}$

HEMPEL, C.G. Explicação Científica. In: . Filo- 
sofia da Ciência, trad. Leônidas Hegenberg, Octany Silveira Da Mota, São Paulo, Cultrix, 1975, p 159-169.

HORGAN, T. \& TYE M. Against The Token Identity Theory. In: . LEPORE, E. \& McLAUGHLIN, B.(eds.), Actions and Events: perspectives on the philosophy of Donald Davidson. Oxford: Basil Blackwell, 1985, p 427441.

HORGAN, T. Physicalism (1). In:

GUTTENPLAN, S. (ed.) A Companion to the Philosophy of Mind. Oxford: Blackwell, 1994, p 471-479.

HUME, D. Tratado da Natureza Humana, trad. Déborah Danowski. São Paulo: Unesp, 2000, 699 p

JOHNSTON, M. Why Having A Mind Matters. In: . LEPORE, E. \& McLAUGHLIN, B.(eds.), Actions and Events: perspectives on the philosophy of Donald Davidson. Oxford: Basil Blackwell, 1985, p 408-426.

KIM, J. Psychophysical Laws. In: . LEPORE, E. \& McLAUGHLIN, B. (eds.), Actions and Events: perspectives on the philosophy of Donald Davidson. Oxford: Basil Blackwell, 1985, p 369-386.

. The myth of nonreductive materialism. In:

Supervenience and mind. Cambridge: Cambridge University Press, 1993, p 265-284.

. Supervenience and mind, Cambridge: Cambridge University Press, 1993b, $215 \mathrm{p}$ $258 \mathrm{p}$

. Philosophy of Mind, Boulder: Westview Press, 1996, 
. Philosophy of Mind and Psychology. In:

LUDWIG, Kirk (ed.). Donald Davidson. Cambridge : Cambridge University Press, 2003, p 113-136.

McDOWELL, J. Mente e Mundo. Trad. J. V. Gallerani Cuter. São Paulo: Ideias \& Letras, 2005, 238 p

McLAUGHLIN, B. Anomalous Monism and the Irreducibility of the Mental. In:__LEPORE, E. \& McLAUGHLIN, B.(eds.), Actions and Events: perspectives on the philosophy of Donald Davidson. Oxford: Basil Blackwell, 1985, p 331-368.

NAGEL, E. The Structure of Science. New York: Harcourt, Brace \& World, xiii, 1961, 618 p.

RORTY, R. Davidson's Mental-Phisical Distinction. Lewis Edwin Hahn (ed.), The Philosophy Of Donald Davidson, 1999, p 575-600.

ROSENBERG, A. Davidson Unintended Attack on Psychology. In:______-_. LEPORE, E. \& McLAUGHLIN, B.(eds.), Actions and Events: perspectives on the philosophy of Donald Davidson. Oxford: Basil Blackwell, 1985, p 399-407. 